\title{
A Research about CPI Fluctuations Effects on Sichuan Vegetable Industry
}

\author{
Rui Liao (Corresponding author) \\ College of Economics \& Management, Sichuan Agricultural University \\ Huimin Road 211" , Wenjiang, Chengdu, China \\ E-mail: liaoruirui89@sina.com
}

Xungang Zheng

College of Economics \& Management, Sichuan Agricultural University

Huimin Road 211" , Wenjiang, Chengdu, China

Received: June 15, 2014 Accepted: July 9, 2014 Published: August 11, 2014

doi:10.5296/ijssr.v2i2.5811 URL: http://dx.doi.org/10.5296/ijssr.v2i2.5811

\begin{abstract}
Sichuan is a major agricultural province in southwest China. Vegetable industry is a new growth point of Sichuan agricultural economy and farmers' income. But in recent years, due to various reasons, Sichuan vegetable industry faces many difficulties. In this paper, fluctuations in the CPI as the starting point, on the basis of the HP filter, using regression analysis and impulse response method to analyze the trend component and fluctuation component separately and get CPI fluctuations on Sichuan vegetable industry long and short term effects. The results show that: in long-term CPI continued to decline slowly can help farmers' income growth and in short-term CPI excessive volatility led to vegetable price, farmers' income, expenditure fluctuate drastic and had a direct impact on the healthy development of Sichuan vegetable industry.
\end{abstract}

Keywords: CPI fluctuations, vegetable industry, HP filter, linear regression, VAR model

\section{Introduction}

Vegetable is the basis food which meets the demand of nutritionally balanced and healthy diet. And also is the main staple food of human life. With the emphasis on healthy diet and continuous optimization of consumption structure, vegetable has become a necessity to 
improve the quality of people's lives. Vegetable has played an irreplaceable important role in our daily life.

China is a large agricultural country which vegetable planting area accounts more than one third of the total area of the world and production accounts more than $40 \%$ of the total world output. China is the world's largest "vegetable basket". Vegetable has obvious comparative benefit compared with other crops. In 2011, the national vegetable output was 679 million tons, more than total grain output of 100 million tons. It output value reached 1.26 trillion Yuan, more than grain output value. The vegetable industry has gradually moved from the former "family garden" into pillar industry of agricultural and rural economic. It has increasing important status in the development of agriculture and rural economy. Sichuan is a major agricultural province in southwest China, with good agricultural conditions, and its agricultural products plays an important role in China. It is known as the "Land of Abundance" reputation. Sichuan vegetable cultivation has a long history and a lot of variety. It is an important vegetable production province.

But in recent years, the development of Sichuan vegetable industry is facing many problems, such as vegetable prices fluctuate greatly, cabbage and lettuce difficult to sell and so on.

At present scholars mainly focused on the relationship between farm price, farmers' income and CPI. There is little research on CPI fluctuations on the vegetable industry. Wang Xiaoli found that CPI and Producer Price Indices of Agricultural Products present similar cyclical fluctuations and have influence on each other. Gao Hongmei through building VAR model analyzed relationship between producer prices of farm products and CPI. She found producer prices of agricultural products have lasting positive impact on the CPI. Xu Qiyuan found vegetables price changes will push CPI changes when he analyzed CPI in 2010.

From previous studies, can find there is a link between the CPI fluctuation and the development of vegetable industry. Hu Ruochi pointed that Producer Price Indices of Agricultural Products, Price Indices of Means of Agricultural Product and CPI have influence on each other. There are positive dialectical relationships between these three. Wang Hanxiao pointed that vegetable prices are affected by inflation factors. At the same time, in response to vegetable prices change, sales and farmers' income will change. Thus, CPI fluctuations will have an impact on the whole industry. So CPI fluctuations as the breakthrough point to study its long-term and short-term effects on producer price of vegetable products, price of means of agricultural products, farmer incomes, planting expenses.

\section{Sichuan Vegetable Industry Development Situation Analyses}

Vegetable industry is an advantage industry and an important part of modern agriculture in Sichuan. It is the backbone of agriculture, farmers' income increasing and rural economic development. Sichuan vegetable production base gradually concentrate to advantage region, showing regional coordinated development pattern and forming Panxi morning vegetables, western Sichuan processed vegetables, southern Sichuan before spring autumn-season vegetables, northeastern Sichuan specialty vegetables, Sichuan-Tibet plateau autumn light vegetables and other advantages regional. Sichuan Province as the country's open field 
vegetables industry base, there are 45 counties (cities, districts) were included in the national key counties in open field vegetable industry, accounting for $7.8 \%$ of the country. 2012 Sichuan vegetable cultivation area of 1241.6 thousand hectares, vegetable production reached 37,503,000 tons. Production has achieved growth for five consecutive years. In first three quarters of 2012, according to estimates, vegetables output value 86.32 billion Yuan, 12.21 billion Yuan more than the same period last year, increased $6.5 \%$. Vegetable output value makes up $21.5 \%$ of agriculture and forestry animal husbandry and fishery output value, increased $1.2 \%$ compared with the same period last year. Vegetable output value of planting industry output value proportion also rose to $35.0 \%$ from $33.4 \%$ during the same period last year, increased $1.6 \%$.

But at the same time in the rapid development of vegetable industry in Sichuan, many problems also emerged: vegetable price fluctuations; seasonal and regional vegetables unsalable such as cabbage, lettuce; low vegetable production scale and organization degree; farmers' income unstable, large risk and so on. These are the serious challenges to the healthy development of Sichuan vegetable industry.

\section{CPI Fluctuations Effects on the Sichuan Vegetable Industry Analysis}

On the one hand CPI fluctuations can cause changes in the agricultural production cost, on the other hand it will also promote the agricultural products retail price fluctuations, and then affect the producer price of agricultural products.

\subsection{Research Methods and Data Sources}

\subsubsection{Method Selection}

Most scholars use VAR model to analyze relationship between CPI fluctuation and farm price. Du Liangsheng adopted VAR model and Granger test to research and pointed inflation affect farm price through three mechanisms. He Puming used VAR to a conclusion that food price index and CPI have positive correlations when he does a research on food price and CPI. In addition, Yang Zhihai, Liu Yong and other scholars took VAR model to analyze agricultural products price and CPI relationship.

Vector autoregressive model (VAR) is an econometric model used to capture the linear interdependencies among multiple time series. It describes the evolution of a set of endogenous variables over the same sample period $(t=1, \ldots, T)$ as a linear function of only their past values. It can review the dynamic effect between variables and need not consider model of endogenous problem. These characteristics make the VAR model especially suitable for the research of price index. The Hodrick-Prescott filter (HP) is a mathematical tool used in macroeconomics, especially in real business cycle theory to separate the cyclical component of a time series from raw data. It used to divide time series into two parts: short-term fluctuation data and long-time trend data. Regression analysis is use mathematical statistics method to estimate the relationships between the dependent variable and independent variable. It helps one understand how the typical value of the dependent variable changes when any one of the independent variables is varied, while the other independent variables are held fixed. The article mainly discusses the CPI current value and lag value's 


\section{Macrothink}

effect on vegetable industry. Therefore, first using HP filter to decompose variables, eliminate trend components. Then use regression analysis to study the relationship between the long-term trends. Last use the VAR model to construct the impulse response function and analysis the impact of the CPI short-term fluctuations.

\subsubsection{Indicators Determination and Data Description}

Other scholars analyze relationship between CPI and price always choose CPI, PI and some others indicators such farmers' income and expenditure. So according to previous research, research demand and purpose, this paper uses CPI, PI, CI, INC, CO time series data as research objects.

CPI: Is short for Consumer Price Index. It measures changes in the price level of a market basket of consumer goods and services purchased by households. In this paper it used to reflect the headline inflation, not core inflation. And headline inflation is calculated from an all-item index and core inflation is commonly calculated from a price index that excludes the highly volatile food and energy components.

PI: Is short for Producer Price Indices of Vegetables. It is a relative number used to reflect the trend and degree of changes in vegetable selling price of vegetable producers in a certain period.

CI: Is short for Price Indices of Means of Agricultural Product. This index use to approximate vegetable production materials price change.

INC: Is short for Rural Household Business Income. Because rural households' vegetable incomes on planting belong to the business income, so the income index used to indicate vegetable incomes movements.

CO: Is short for Expenditure for Rural Household Business. Rural households' vegetable spending on planting belongs to the expenditures for business, so expenditures index used to indicate changes in vegetable cultivation expenses.

Considering the research demand and data validity, authority, this paper chose statistical data. All the data is from 2007-2012 "China Monthly Economic Indicators". And because of PI just have quarterly data report, so all the indicators use quarterly time series data. The flowing figure describes the quarterly data move during 2007-2012. And from this figure we can find PI, CI, INC and COS fluctuate around CPI. 


\section{Macrothink}

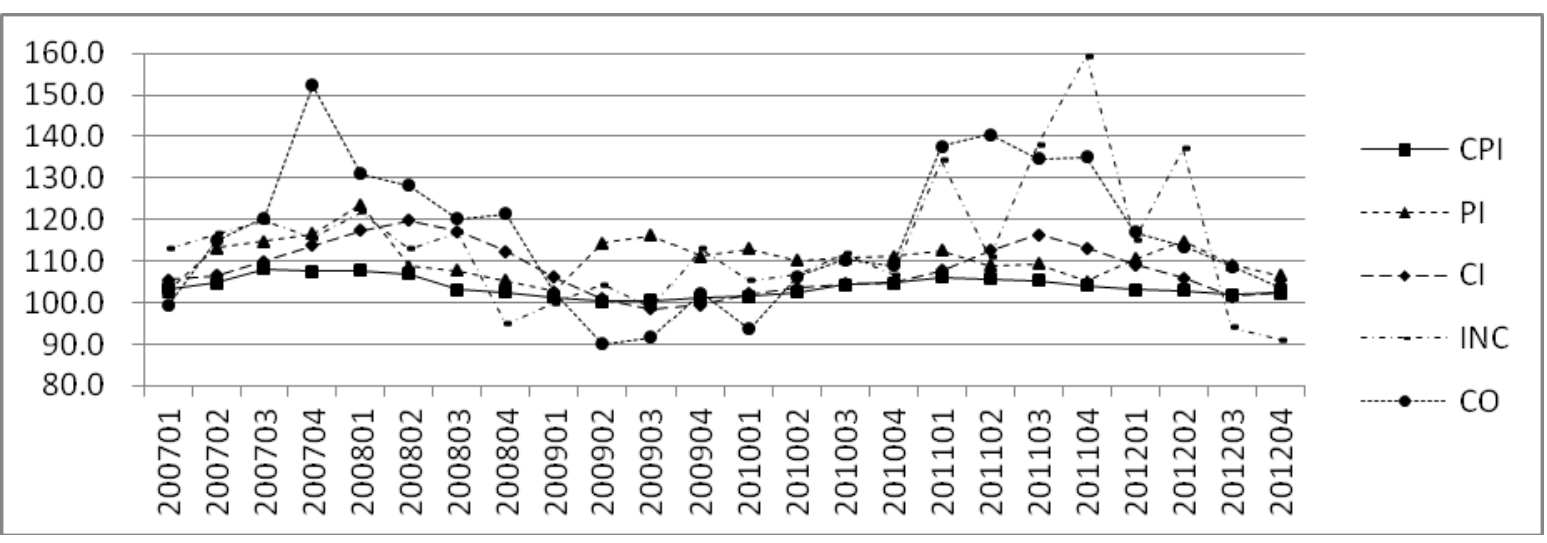

Figure 1. Data Move

\subsection{Relationship between the Long-Term Trend Analysis}

\subsubsection{Indicators Decomposition}

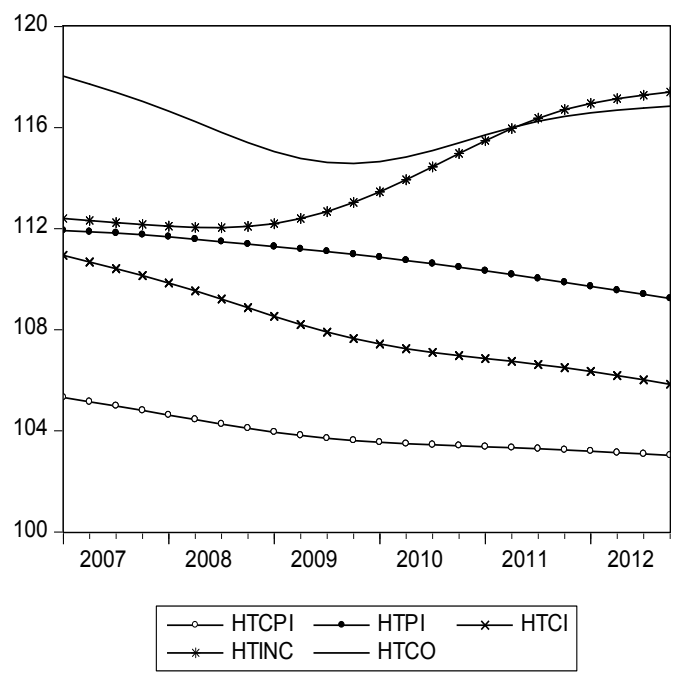

Figure 2. Indicators trend component

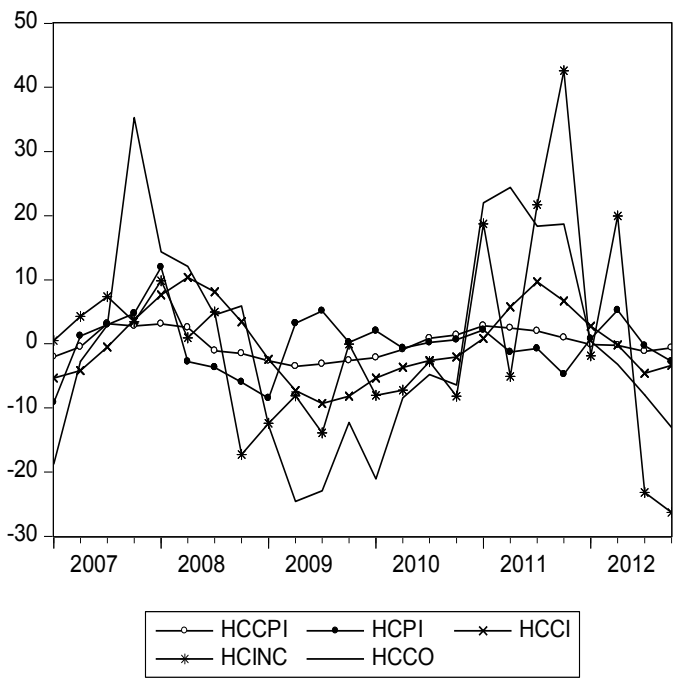

Figure 3. Indicators fluctuation component

HP filter method used to decompose CPI, PI, CI, INC and CO into the time series trend component (Figure 2) and volatility component (Figure 3). In the following, use HTCPI, HTPI, HTCI, HTINC and HTCO respectively on behalf of CPI, PI, CI, INC, CO trend component. Use HCCPI, HCPI, HCCI, HCINC and HCCO respectively on behalf of CPI, PI, $\mathrm{CI}$, INC, $\mathrm{CO}$ volatility component.

Figures 2 and 3 showed that: (1) Overall trend on CPI, PI, CI basically are similar. Both showed a gradual decline trend. But INC is a general upward trend and CO has no consistent trend, first decreased and then increased. (2)From volatility composition figure, five variables have shown significant fluctuations along with time. And CPI fluctuation range is relatively small. PI, CI, INC, CO fluctuates around the CPI significantly, especially INC and CO fluctuation range are far more than the CPI fluctuation range. 


\subsubsection{Linear Regression Analysis}

A linear regression analysis is under the condition of the exclusion of all other factors or assumes other factors determine. It used to analysis one factor (explanatory variables) affect the other factor(the dependent variable) process.

$$
\mathrm{Y}_{\mathrm{i}}=\alpha_{\mathrm{i}}+\beta_{\mathrm{i}} \mathrm{X}+\mu_{\mathrm{i}} \quad(\mathrm{i}=1,2,3,4)
$$

$\alpha_{\mathrm{i}}$ and $\beta_{\mathrm{i}}$ are parameters to be estimated. $\mu_{\mathrm{i}}$ is random disturbance term.

HTCPI as the explanatory variable, HTPI, HTCI, HTINC, CO HTCO respectively be dependent variable to construct linear regression equation. Use eviews6.0 for linear regression analysis. The results are shown in Table 1:

Table 1. Regression results table

\begin{tabular}{cccccc}
\hline Model & $\begin{array}{c}\text { dependent } \\
\text { variable }\end{array}$ & Coefficient & Constant & $\begin{array}{c}\text { R } \\
\text { Square }\end{array}$ & F \\
\hline 1 & HTPI & $1.096(10.21)$ & $-2.983(-0.27)$ & 0.83 & 104.30 \\
2 & HTCI & $2.271(36.01)$ & $-127.803(-19.52)$ & 0.98 & 129.84 \\
3 & HTINC & $-2.350(-6.33)$ & $358.087(9.29)$ & 0.65 & 40.03 \\
4 & HTCO & $0.683(2.48)$ & $45.128(1.58)$ & 0.22 & 6.145 \\
\hline
\end{tabular}

Note: Explanatory variable is HTCPI, () is t-statistics.

Model 1,2,3,4 respectively show long-term trend linear relationship between CPI and PI, CI, INC, CO. Table 1 show, HTCPI and HTPI, HTCI, HTCO are positive linear relationship. Indicate that HTCPI, HTPI, HTCI and HTCO change in same direction. When CPI raised 1 unit, vegetable producer prices will raise 1.096 units, production material prices will raise 2.271 units and production spending will raise 0.683 units. But HTCPI and HTINC have a negative linear relationship and indicate that when CPI raised 1 unit will lead to farmer income reduce 2.350 units. This is mainly because vegetable producer price rise less than means of agricultural production price when CPI rise. This phenomenon will cause farmer income reducing.

\subsection{Analysis of Short-Term Fluctuations Effects}

\subsubsection{Model Building}

Use the vector auto-regression model to analyze the CPI short-term fluctuations in Sichuan vegetables industry. Vector auto-regression general mathematical expression is:

$$
\mathrm{y}_{\mathrm{t}}=\mathrm{A}_{1} \mathrm{y}_{\mathrm{t}-1}+\ldots \mathrm{A}_{\mathrm{p}} \mathrm{y}_{\mathrm{t}-\mathrm{p}}+\ldots \mathrm{B}_{1} \mathrm{x}_{\mathrm{t}}+\ldots \mathrm{B}_{\mathrm{r}} \mathrm{x}_{\mathrm{r}-\mathrm{p}}+\mathrm{e}_{\mathrm{t}}(\mathrm{i}=1,2,3,4)
$$

$\mathrm{y}_{\mathrm{t}}$ is an $\mathrm{m}$-dimensional endogenous variables and $\mathrm{x}_{\mathrm{t}}$ is a d-dimensional exogenous variables. $A_{1} \ldots A_{p}$ and $B_{1} \ldots B_{r}$ are parameter matrix to be estimated. Endogenous and exogenous variables respectively $\mathrm{p}$ and $\mathrm{r}$ lag phase. $\mathrm{e}_{\mathrm{t}}$ is a random disturbance term.

HCCPI as the explanatory variable, HCPI, HCCI, HCINC, HCCO respectively be dependent 
variable to construct VAR model.

\subsubsection{Data Stationarity Test}

In order to ensure the unbiasedness, effectiveness and robustness of the regression results, this paper adopts the Augmented Dickey-Fuller (ADF) test method to do the stationarity test. Use eviews6.0 for each of the variables unit root test. The test results are shown in Table 2:

Table 2. Unit root test results

\begin{tabular}{|c|c|c|c|c|c|c|}
\hline \multirow{2}{*}{ Variable } & \multirow{2}{*}{$\begin{array}{l}\text { Test type } \\
(\mathrm{c}, \mathrm{t}, \mathrm{n})\end{array}$} & \multirow{2}{*}{$\begin{array}{l}\text { ADF } \\
\text { value }\end{array}$} & \multicolumn{3}{|c|}{ Critical values } & \multirow{2}{*}{ Stationarity } \\
\hline & & & $1 \%$ & $5 \%$ & $10 \%$ & \\
\hline HCCPI & $(0,0,0)$ & -1.913 & -2.692 & -1.960 & -1.607 & steady \\
\hline HCPI & $(0,0,0)$ & -5.844 & -2.686 & -1.959 & -1.607 & steady \\
\hline $\mathrm{HCCI}$ & $(0,0,0)$ & -4.728 & -2.674 & -1.957 & -1.608 & steady \\
\hline HCINC & $(0,0,0)$ & -3.497 & -2.686 & -1.959 & -1.607 & steady \\
\hline $\mathrm{HCCO}$ & $(0,0,0)$ & -2.221 & -2.669 & -1.956 & -1.608 & steady \\
\hline
\end{tabular}

\subsubsection{Model Estimation Results}

On basis of minimum criteria of the LLC statistic, Akaike information criterion (AIC) and Schwarz criterion (SC) determining the optimal number of lags is 4 . The VAR model estimation results are as follows:

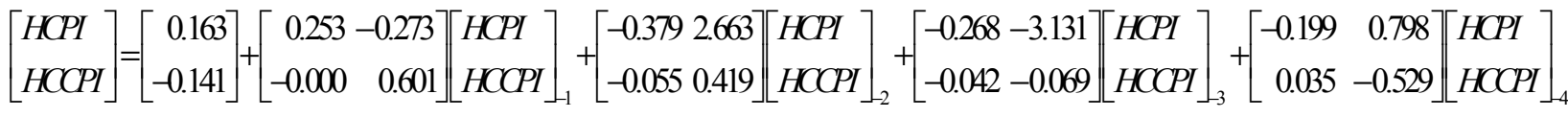

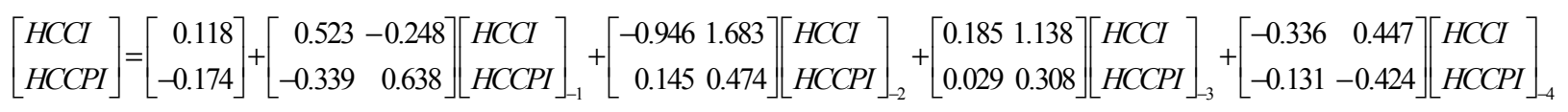

$$
\begin{aligned}
& {\left[\begin{array}{l}
\text { HCINC } \\
\text { HCCPI }
\end{array}\right]=\left[\begin{array}{l}
-0.305 \\
-0.230
\end{array}\right]+\left[\begin{array}{ll}
-0.038 & 2.888 \\
-0.003 & 0.617
\end{array}\right]\left[\begin{array}{l}
\text { HCINC } \\
\text { HCCPI }
\end{array}\right]_{-1}+\left[\begin{array}{ll}
0.312 & 1.425 \\
0.021 & 0.183
\end{array}\right]\left[\begin{array}{l}
\text { HCINC } \\
\text { HCCPI }
\end{array}\right]_{-2}+\left[\begin{array}{ll}
0.004 & -1.318 \\
0.012 & 0.077
\end{array}\right]\left[\begin{array}{l}
\text { HCINC } \\
\text { HCCPI }
\end{array}\right]_{-3}+\left[\begin{array}{rr}
-0.887 & 1.956 \\
0.004 & -0.605
\end{array}\right]\left[\begin{array}{l}
\text { HCINC } \\
\text { HCCPI }
\end{array}\right]_{-4}}
\end{aligned}
$$

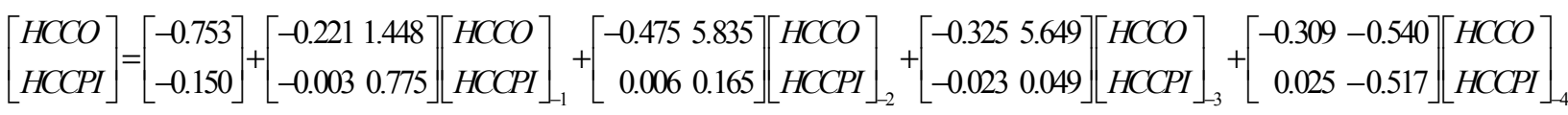

\subsubsection{Impulse Response Function Analysis}

Impulse response function is useful for studying the interactions between variables in a vector autoregressive model. It represent the reactions of the variables to shocks hitting the system and can be relatively visually depicts the dynamic interaction between the variables. Respectively use impulse response function to analyze HCPI disturbance for HCCPI, HCCI, HCINC, and HCCO. The results are shown in Figure 3, Figure 4, Figure 5 and Figure 6. 


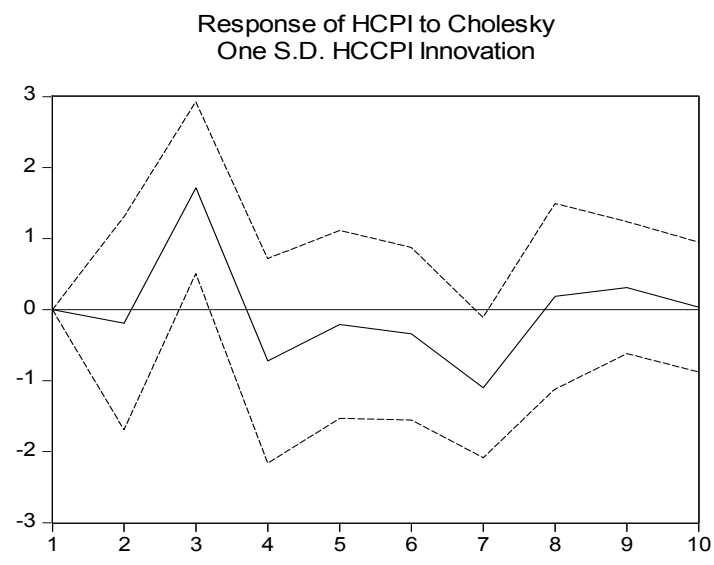

Figure 4. Response of HCPI to HCCPI

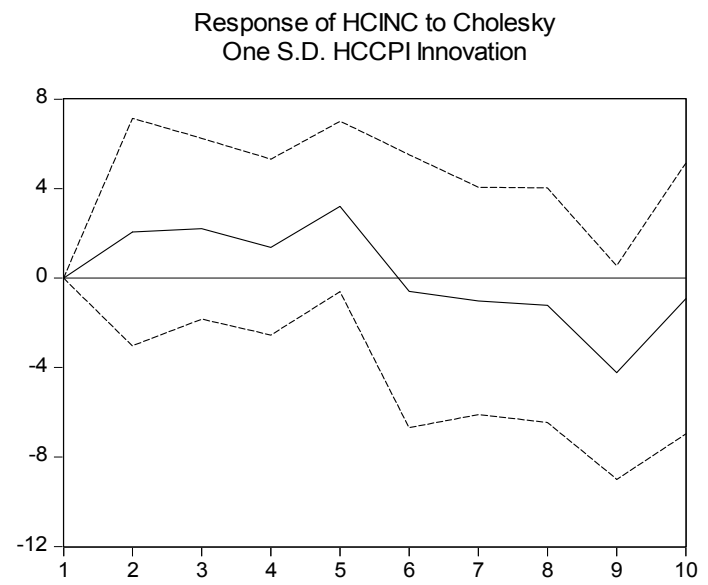

Figure 6. Response of HCINC to HCCPI

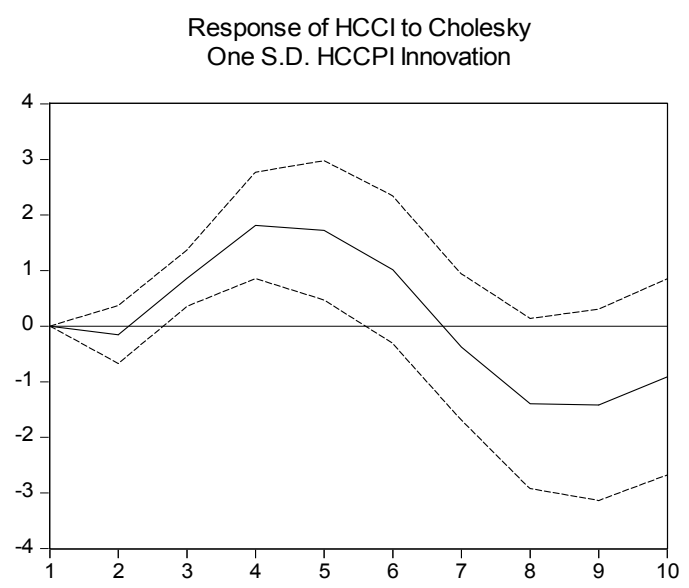

Figure 5. Response of HCCI to HCCPI

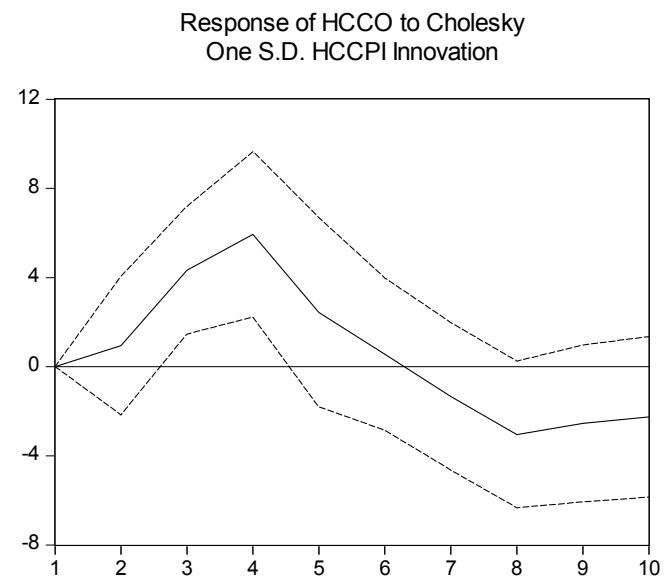

Figure 7. Response of HCCO to HCCPI

Observe figure 4 to figure 7, found that: (1) HCPI, HCCI, HCINC, HCCO in phase 1 do not respond to the shock of HCCPI. (2) HCPI and HCCI in phase 2 begin a weak negative response, and then show an upward trend. HCPI peaks at phase 3, close to 2, and then decrease gradually. In phase 4 turn to negative effects, reach its lowest point in phase 7 , around -1 , and then begin to grow. In phase 8 turn to positive impact, and response amplitude is gradually shrinking. HCCI peaks close to 2 in phase 4 and begin show a gradual downward trend in phase 5. From phase 7 to negative effects, phase 8 reach its lowest point, around -1.8 , follow by another rising trend. Overall HCCPI has obvious impact and pushing effect on HCPI, HCCI. HCCPI change a unit will cause HCPI, HCCI move close to two units. Furthermore HCCPI stimulating effect on HCCI persistent much longer, slower and more stable than the stimulating effect on the HCPI. (3) HCINC, HCCO in phase 2 have relatively obvious positive response, and on upward trend. HCINC is rising steadily and in phase 5 achieve positive peak, around 3, then into a downward trend. From phase 6 to negative effects, in the phase 9 reach its lowest point, about 4 . HCCO is rising fast and in phase 4 it 
peaks, close to 6 . Then drop quickly, from phase 6 to negative effects, and in the phase 8 reached its lowest point, at about 3. Overall HCCPI pull function on the HCINC, HCCO are positive. Pulling range and sustainability is long and in comparison the $\mathrm{HCCO}$ pulling range is greater than HCINC.

\section{Conclusions and Suggestions}

\subsection{Conclusions}

Through regression analysis of the trend components and impulse response analysis of volatility components, can draw the following conclusions:

1) Long-term trends show: CPI continued to reduce led to farmers' income growth accelerated and sustained growth resulted in farmers income' growth slowdown. CPI and PI, $\mathrm{CI}, \mathrm{CO}$ were positive linear relationship, but CPI and INC was negative linear relationship. In this paper, indexes' long-term trend components were relative number which were greater than 100. CPI decreased, INC would increase, so cash income growth expansion and accelerated. At the same time when CPI decreased PI, CI, INC would reduced and the corresponding vegetable producer price, price of means of agricultural production, expenditure for rural household business growth slowed down. On the contrary, the CPI raised, cash income growth reduced and slowed down, vegetable producer price, price of means of agricultural production, expenditure for rural household business growth rate would expand and accelerated. This might be because when the CPI changes the vegetable production price will change, then will cause vegetable retail price bigger fluctuations, at last vegetable consumption and sales will change, so lead to the reduction in income growth or amplification.

2) Short-term fluctuations shows: CPI short-term component excessive volatility would lead to vegetable production price, farmers' income and expenditure shocking. CPI fluctuations could cause PI, CI, INC and CO more substantial fluctuations and had a positive role to these. CPI fluctuations led to vegetable producer price, price of means of agricultural production, expenditure for rural household business and rural household business income choppy in the short term.

3) The CPI excessive volatility was bad for farmers' stable profit growth and the healthy development of Sichuan vegetable industry. Farmers profit problem is the key problem for the development of vegetable industry. 2007-2012 trend data showed CPI index in a continuous downward state, cash income in a state of upward. This was more conducive to the development of Sichuan vegetable. But when the CPI continues to upward farmers will face vegetable producer price, price of means of agricultural production and expenditure for rural household increase sharply, but a small increase in rural household business income. So profits may reduce gradually, affect the enthusiasm of farmers planting and development of vegetable industry. On the other hand, the CPI fluctuation would lead to price, income, spending a larger fluctuation, and income volatility smaller than spending volatility. This increased the risks of farmers planting, generated uncertainty. It led to guarantee profits difficult, and may also affect the healthy development of Sichuan vegetable industry. 
4.2 Suggestions

1) Understand the vegetable price fluctuations should consider the macro environment. On the above analysis found that fluctuations in the prices of vegetables and CPI fluctuations had closed relationship. The change of the CPI would largely promote the change of the vegetable prices, so you can't just only look at vegetables price fluctuations, should put the fluctuations in the macro environment to consider.

2) Improve the organization degree of farmers. A family of individual independent production is the main form of vegetable production. Vegetable farmers under this form dispersion degree are high and resist risk ability are poor. Increase the degree of farmers organization, for farmers, one can improve the ability of resist market changing, the second is to strengthen its competitive position in the market, protect their legitimate rights and interests, and share the economies of scale various benefits.

3) Increase the intensity of fiscal and financial support for vegetable production. Compared with other agricultural activities, vegetable production cost is high and risk is big. To support the vegetable production, increase the fiscal and financial fund support of vegetable production. Implementation production subsidies for vegetable production, increase vegetable production investment, vegetable production incentives and other measures, in order to reduce price fluctuations and seeds, fertilizer, pesticide and other agricultural materials price fluctuation influence on profit of farmers, in order to improve the farmers level of profitability and arouse the enthusiasm of the production.

\section{Acknowledgement}

Papers completed got a lot people's help and care. I think should express my gratitude to them. First of all thank my tutor's careful indicators, and secondly to thank the anonymous reviewers' comments, the last to thank the classmates for help and support.

\section{References}

580 key county of vegetables industry. China Vegetables, 5.

Du Liangsheng, Zhou Bin, \& Duan Pengfei. (2012). On interaction mechanism of agricultural product price and inflation. Economic Theory and Business Management, 6, 23-33. 10.3969/j.issn.1000-596X.2012.06.003

He, P., \& Zhu, X. (2012). The empirical study of China's grain price fluctuation relationship with CPI. Journal Agricultural Technology Economics, 2, 83-87.

Huang, W., Xu, X., \& Wu, Y. (2012). Analysis on transmission mechanism between agrecultural production price, grain price and rural CPI: based on perspective of agricultural chain. Technology Economics, 6, 107-112. 10.3969/j.issn.1002-980X.2012.06.017

Hu, R., Chen, X., \& Chen, H. (2013). Analysis on the Change of China CPI and Related Agricultural Product Pricing Index. Journal of Beijing City University, 1, 34-39.

Li, Z. (2005). Econometrics (2nd ed.). Beijing: Higher Education Press. 


\section{Macrothink}

International Journal of Social Science Research

ISSN 2327-5510

2014, Vol. 2, No. 2

National Vegetable Industry Development Plan. (2011-2020). China Vegetables, 5, 1-12.

Wang, H., An, Y., \& Long, X. (2009). China's vegetable supply: demand and pricemovements Analysis. China Vegetables, 15, 6-8.

Xing, Z. (2012). Price fluctuations on the vegetable industry in Shandong province. Shandong Agricultural University.

Zhang, Y., \& Wu, T. (2011). The cause of the price fluctuation of agricultural products,effects and countermeasures-In Case of Wuwei City. Gansu province. Productivity Research, 8, $30-32$.

Gao, H., \& Zhou, Z. (2013). Empirical research of the relationship between China's agricultural price index and CPI based on VAR model. Guangdong Agricultural Sciences, 9, 205-208.

Furlong, F., \& Ingenito, R. (1996). Commodity Prices and Inflation. FRBSF Economic Review, 2, 27-46.

Liu, Y., Wang, W., \& Yi, F. (2009). Dynamic Relations Analysis between China's Inflation, Agricultural Products and Economic Growth. Ecological Economy, 2, 61-65.

\section{Copyright Disclaimer}

Copyright for this article is retained by the author(s), with first publication rights granted to the journal.

This is an open-access article distributed under the terms and conditions of the Creative Commons Attribution license (http://creativecommons.org/licenses/by/3.0/). 